\title{
Identification of the level of innovativeness of a complex major construction project
}

\author{
Violetta Politi* \\ Moscow State University of Civil Engineering, Yaroslavskoe shosse, 26, Moscow, 129337, Russia
}

\begin{abstract}
The complexity of a project as a system is characterized by the variety of elements and the number of possible initial and future states. It is possible to give an accurate mathematical description of a complex system based on the study of entropy. The entropy of states is defined as a measure of the diversity of the set of possible options. A construction project that includes a large number of heterogeneous innovative components belongs to the group of complex projects. The problem of control is to reduce its diversity by reducing the set of all states to a subset of states that satisfy the goals of control. Consequently, the essential characteristics of the innovativeness of a construction project should be studied in relation to the sphere of occurrence of the effect from the application of innovations. It seems logical to consider the effects of the introduction of innovations throughout the life cycle of an investment and construction project, which can be presented as an integral production and economic system.
\end{abstract}

\section{Introduction}

The construction industry, having certain organizational, economic, technical and technological features, peculiarities of pricing for construction work and services, is also characterized by the specificity of the perception of an innovative product. Sluggishness, lack of economic incentives, fragmentation of construction participants, delay in standardization of innovations, long periods of approval of design estimates and design documentation, and, in general, low commitment to innovation are the source of the fact that the rate of innovation implementation and the rate of growth of labor productivity are extremely low compared to the world economy as a whole.

The characteristic of the construction industry as an "innovative conservative" is explained precisely by its specificity - the length of the production cycle for the implementation of the investment project, a huge number of participants, high risks and a long payback period for the customer's (investor's) invested capital. The so-called "innovative slowness" of the participants in the investment and construction process is explained by their autonomy in relation to each other, while the level of system integration,

* Corresponding author: polity_violca@list.ru 
interest in the results of the final construction product (creation of fixed assets), for example, even in housing and civil construction, is very insignificant. Therefore, the main obstacle to the introduction of innovations in the construction industry is the multidirectional vectors of economic interests of all participants in the investment and construction cycle of creating fixed assets for production and non-production purposes [14].

The products of the construction industry are the individual construction and installation works performed and the services provided during the period of the work contract. Each participant acts as a specific link in the value chain, namely, the value of the finished object. However, only one of the many participants in the investment and construction cycle is showing commercial interest in the innovative characteristics of the future facility the customer (investor), as well as the future consumer (purchaser) of the construction industry products.

At the same time, the participants in the infrastructure support of construction are embedded in an even wider value chain created by the market of finished objects and structures (real estate) [2,3]. At the same time, the real estate market itself is not ready to stimulate radical product and technological innovations, since it has no grounds for this, possibly due to the unpreparedness of the average consumer and his low commitment to innovation. However, the innovative development of the construction industry as a whole depends on the economic interest of each participant in production activities in the implementation of innovations.

The state, as an integrator of the commercial interests of subjects of economic relations (entrepreneurs) and innovation processes, should act as a unifying force capable of leveling the unevenness of economic claims and redirecting the target "entrepreneurial vectors" of participants in one direction (Fig. 1).

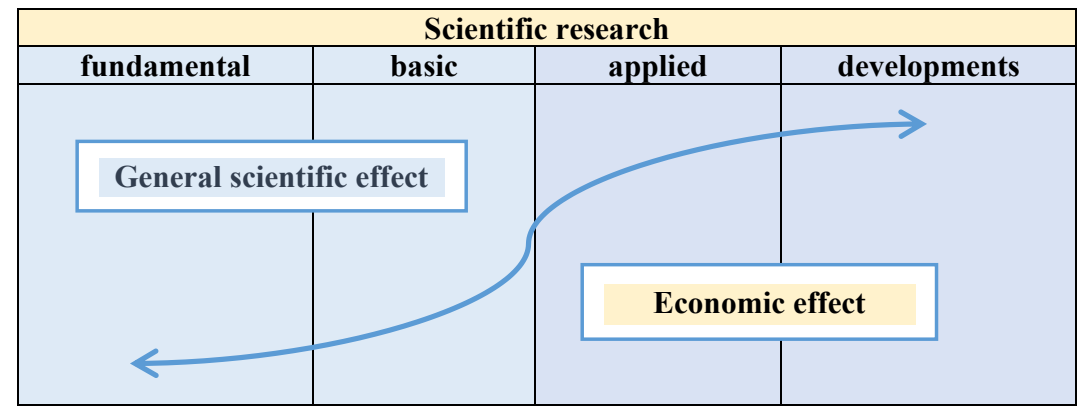

Fig. 1. Correlation of types of effects arising at different stages of innovation creation.

\section{Materials and Methods}

Representation of a project as a temporary enterprise, according to most international or national standards for project management, also creates a "temporary" relationship to the process and results of labor. At the same time, focusing not on the project itself, but on the value that it creates for the participating companies and for society as a whole, increases responsibility for the result, activity and commitment to innovation [5-8].

Usually, a project, according to the descriptions of international and national standards of America and European countries, is defined as a set of actions leading to the creation of a product or service in conditions of limited time, human and material resources.

The innovation of the Japanese system was that the goal was not the product, but the value it brought to the corporation and how it improved the state of the company and 
society. The core of the standard's methodology is the following trilemma: complexity, value, and resistance. This complex syllogism with mutually exclusive assumptions perceived as a break in a logical chain reflects the content of the essence of the development process itself, the significance and implementation of innovation. Therefore, the Japanese P2M standard can be taken as the basis for national standards for the management of innovative projects in construction for the Russian conditions. The Japanese P2M standard is designed to help companies operate in an unstable and hostile environment. One of the main qualities inherent in successful companies according to the Japanese standard is flexibility, adaptability to changes [7-10].

Of course, for Russian national conditions, direct copying of foreign experience is unacceptable and requires the development of our own standard for managing a construction project with an innovative component (Table 1).

Table 1. Brief description of the basic principles of project management

\begin{tabular}{|l|l|l|}
\hline $\begin{array}{l}\text { Project management } \\
\text { principles according to } \\
\text { Japanese standards }\end{array}$ & $\begin{array}{l}\text { Project management } \\
\text { principles according to } \\
\text { Western European } \\
\text { standards }\end{array}$ & $\begin{array}{l}\text { Construction project } \\
\text { management principles for } \\
\text { Russian conditions } \\
\text { [developed by the author] }\end{array}$ \\
\hline Process orientation & Results orientation & $\begin{array}{l}\text { Focus on a process that } \\
\text { contributes to the creation of a } \\
\text { unique product }\end{array}$ \\
\hline $\begin{array}{l}\text { Striving to improve } \\
\text { standards }\end{array}$ & Ensuring standards & Ensuring standards \\
\hline $\begin{array}{l}\text { Adaptation and } \\
\text { improvement }\end{array}$ & Innovations & Innovation and improvement \\
\hline Personnel orientation & Technology orientation & Focus on human capital \\
\hline Attention to details & $\begin{array}{l}\text { Attention to major } \\
\text { transformations }\end{array}$ & Attention to details \\
\hline $\begin{array}{l}\text { Use of existing } \\
\text { technologies }\end{array}$ & $\begin{array}{l}\text { Search for new } \\
\text { technologies }\end{array}$ & $\begin{array}{l}\text { Creation and use of new } \\
\text { technologies }\end{array}$ \\
\hline $\begin{array}{l}\text { Focus on training and } \\
\text { using general managers }\end{array}$ & $\begin{array}{l}\text { Narrow specialization } \\
\text { of managers }\end{array}$ & $\begin{array}{l}\text { Systems knowledge and strategic } \\
\text { thinking among managers, design } \\
\text { engineers, construction engineers }\end{array}$ \\
\hline $\begin{array}{l}\text { Close relationship } \\
\text { between design } \\
\text { personnel and } \\
\text { production line } \\
\text { personnel }\end{array}$ & $\begin{array}{l}\text { Clear separation } \\
\text { between design and } \\
\text { production line } \\
\text { personnel }\end{array}$ & $\begin{array}{l}\text { Interconnection and } \\
\text { synchronization of actions of all } \\
\text { participants in the implementation } \\
\text { of a construction project }\end{array}$ \\
\hline $\begin{array}{l}\text { Openness of } \\
\text { information for } \\
\text { company members }\end{array}$ & Privacy of information & $\begin{array}{l}\text { Openness of information for } \\
\text { company members and project } \\
\text { participants }\end{array}$ \\
\hline $\begin{array}{l}\text { Strong collectivism } \\
\text { individualism }\end{array}$ & $\begin{array}{l}\text { Expressed collectivism while } \\
\text { respecting the sovereignty of each } \\
\text { participant }\end{array}$ \\
\hline
\end{tabular}

Taking into account the above definitions, the proposed method for identifying economic effects from the introduction of innovations in construction will be based on a process approach, and therefore should be based on an assessment of the full life cycle of an innovation-oriented construction project.

The following main areas of the technical and economic assessment of a complex innovation-oriented construction project (IOCP) can be distinguished: 
1. Identification of an investment and construction project as an innovative project. Identification and assessment of the level of innovativeness of the construction (reconstruction) project of buildings or structures.

2. Assessment of the investment attractiveness of the implementation of IOCP throughout its entire life cycle (initiation, marketing research (innovation, market, consumers), design, construction, operation).

3. Recognition/rejection of the project as an "innovation-oriented construction project". Making a decision on the level of investment attractiveness of an innovation-oriented construction project.

4. Assessment of the economic effects from the introduction of innovations by each economic unit participating in the implementation of IOCP (it can be assumed that this will be an assessment of the introduction of organizational and marketing innovations as a lever to increase the level of competitiveness). Here, the author is supposed to assess organizational and management innovations.

Nowadays, in international and Russian practice, there is a sufficient number of universal and specific industry approaches to assessing the effectiveness of innovations, including innovative projects. However, the problem of introducing and intensifying the use of innovations remains relevant $[11,12]$.

\section{Results}

The interest of the customer (investor) in the implementation of a project for the construction of an object with signs of innovation must be substantiated by technical and economic calculations at the stage of developing a feasibility study of the project (FS).

Innovative construction projects have a number of characteristics that are unattractive for the investor, these include: the technological and organizational complexity of the construction of the building, the need to use new construction equipment and highly qualified personnel, the high price of a construction contract, a long payback period, a high level of risk and high level of corruption. Therefore, the customer's interest should have state support, which can be expressed in obtaining certain preferences and incentives if innovations are inherently present and are an integral part of an investment and construction project. The development of mechanisms of state financial support for innovative activities, such as concessional lending, the creation of direct investment funds, legal regulation of venture capital funds, will create favorable conditions for eliminating the shortage of innovative projects.

Therefore, the author of this study considers it necessary to develop a methodology for substantiating and assessing the economic efficiency of a project with a high level of innovation, capable of generating high added value.

Below is an algorithm for the development and substantiation of an innovation-oriented construction project (IOCP) financed with the involvement of budgetary funds on a repayable basis.

STAGE 1. Substantiation of the strategic importance of an innovation-oriented construction project (industry-wide, regional level)

$\circ$ the presence of a planned contribution to the achievement of the goals of the sectoral strategy, regional development strategy and target indicators of state programs, as well as the presence (absence) of potential restrictions for the successful implementation of the investment project.

$\circ$ the presence of potential limitations for the successful implementation of an investment project. 
STAGE 2. Substantiation of the strategic importance and identification of zones of occurrence of the effects of participants in the investment and construction pool (the level of the developer company, contractor, subcontractor, consumer)

○ Zone of the main production activity: application of innovative methods of organization and technology of construction work; the use of innovative building structures and materials.

o Zone of results of production and construction activities: the creation and operation of buildings with improved space-planning and structural solutions, with new building materials and equipment.

○ Intra-organizational zone: application of marketing innovations; innovative restructuring of the management system.

Incentives for the use of innovations in the construction of a complex construction facility:

The main effects of the developer-customer (investor):

- reduction of the construction period of the facility (economic effects: release of production capacity, acceleration of the turnover of working assets, reduction of the period of investments' stay in work in progress, reduction of the payback period of capital investments);

- improving the quality of work performed and the object itself;

- growth in the rate of consumer properties of finished construction products;

- reduction of operating costs arising from the operation of the future facility;

- improving the image of a development company (customer-developer; investor) and increasing its competitiveness;

- improving procedures for selecting a contractor;

- development of information technologies and telecommunication technologies;

- increasing labor productivity and qualifications of the staff;

- increasing the level of safety in the implementation of construction and installation work;

- reduction of harm to the environment;

- motivation for innovation.

Concurrent effects, including the effects of the consumer of construction products:

- formation of a new look of the building and new attractive architectural and planning solutions;

- giving the object innovative consumer properties (increased comfort and safety of staying in the premises);

- formation of new modern operational capabilities for consumers;

- greening of construction products for industrial, housing and civil purposes;

- increasing customer satisfaction with construction products;

- other effects created by innovation.

STAGE 3. Diagnostics and assessment of the level of innovativeness of an investment and construction project (socio-economic and technological aspects)

3.1. The innovativeness of the project will mean, firstly, the intensity of the use of technological and product innovations in the working and design documentation, such as architectural and planning solutions for an object or for a development complex, applied innovative building materials, structural solutions of the building, as well as selected technological equipment and life support systems (passenger elevators, ventilation system, water supply system, drainage system, etc.).

Secondly, the indicator of the level of innovativeness of the project, as a process of creating the main fund for production or non-production purposes, is determined by the ability to change the main characteristics of the human environment.

According to the definition of J. Schumpeter, the degree of innovativeness of an object is determined by the share of the contribution that it makes to the acceleration of the 
qualitative improvement of the objects associated with it. That is, innovativeness is determined not so much by novelty as by the impulse of development that is able to bring the project into the given socio-economic system of human life.

The essential characteristics of the innovativeness of a construction project should be studied in relation to the sphere of occurrence of the effect from the application of innovations (production effect; effect during the operation of the facility; associated economic effect). It seems logical to consider the effects of the application of innovations throughout the entire life cycle of an investment and construction project, which can be represented as an integral production and economic system with the following properties: complexity of the hierarchical structure, the influence of subjective and objective factors, emergence, dynamism, complexity of information flows, multiplicity goals of subsystems, multifunctionality of elements.

The specified properties of the project as a system determine the need for a systematic approach to project management, which involves considering the elements of the project and their functioning in interrelation and interdependence. The complexity of a project as a system is also characterized by such an indicator as diversity (system entropy). The control problem, therefore, is to reduce its diversity by reducing the set of all states to a subset of states that satisfy the control goal.

3.2. Let us present the above point of view in the form of two enlarged models, with the help of which it is possible to determine the areas of the methodological approach, which can allow, on a qualitative and quantitative level, identifying the essence and properties of the concept of innovativeness of a construction project and its ability to influence the state and development of the production and economic system.

As you know, a system is a complete, integral set of elements (components) interconnected and interacting with each other so that the function of the system can be realized. Thus, the system $S$ is an ordered pair $S=(X, R)$, where $X$ is a set of elements; $R$ is the set of relations between $X$.

The production and economic system will be considered as a dynamic object characterized by a sequence of changes in its states in time. The changes will be set by innovations that are consistently applied at the stages of construction work at the facility, as well as used in the operation of the finished building.

The first model determines the coefficient of innovativeness of each element of the system, which is assessed by the contribution to the acceleration of the qualitative development of the entire production and economic system for the analyzed period:

$$
\mathrm{K}_{\mathrm{Inn}}(\mathrm{X})=\sum_{\mathrm{t}=1}^{\mathrm{T}} \sum_{\mathrm{r}=1}^{\mathrm{a}} \overrightarrow{\mathrm{a}}(\mathrm{r})
$$

$\mathrm{K}_{\mathrm{Inn}}$ - coefficient characterizing the level of innovation of a system element;

$\mathrm{X}$ - element whose innovativeness is measured; $\overrightarrow{\mathrm{a}}$ - acceleration of development, which element $\mathrm{X}$ provides to the system; $\mathrm{r}$ - parameters used to assess the acceleration of quality; $\mathrm{T}$ - calculation horizon measured in steps; $\mathrm{t}$ - calculation step (month, quarter, year).

In this case, the acceleration of development is a qualitative characteristic of an element of the system, and from a mathematical point of view, acceleration is a vector characteristic of uneven motion, which is determined by the formula:

$$
\overrightarrow{\mathrm{a}}=\frac{\mathrm{v}_{1}-\mathrm{v}_{0}}{\mathrm{t}}=\frac{\Delta \mathrm{v}}{\mathrm{t}}
$$

$\mathrm{v}_{0}, \mathrm{v}_{1}-$ initial and final speed indicators (in this case, these are the physical parameters of an element of the socio - economic system); $t-$ period of change of indicators; 
if $\mathrm{a}>0$, then the movement is accelerated and $\mathrm{v}$ increases,

if $\mathrm{a}>0$, then motion is slow and $\mathrm{v}$ decreases.

The direction of the acceleration vector will coincide with the direction of change in speed. The purpose of the first factor is to measure the innovative potential of each element.

With the help of the second model, it is supposed to determine the coefficient of innovativeness of the entire project as a production and economic system. The purpose of the coefficient is to characterize and assess the acceleration of the development of the system according to the given parameters:

$$
K_{\text {Inn }}(S)=\sum_{t=1}^{T} \sum_{r=1}^{A} A(r)
$$

$K_{\text {Inn }}$ - coefficient of innovativeness; $S$ - production and economic system; $A-$ acceleration of the qualitative development of the production and economic system, assessed by changes in the specified parameters; $r$ - parameters by which the acceleration of the qualitative development of the production and economic system is assessed.

The above enlarged models are designed to demonstrate the fundamental possibility of measuring the innovativeness of heterogeneous objects and systems.

3.3. The development of an innovative investment and construction project begins with the issuance of a design assignment, which indicates the required characteristics of the object.

At the design stage, the future placement of objects, their technical, structural and space-planning solutions are determined, and as a result, the effectiveness of capital investments is assessed. The use of a system for assessing technical and economic indicators and choosing the best design solution according to the criteria of innovationefficiency-feasibility allows reflecting the influence of functional, technical, technological and organizational factors of an innovative project on economic results.

Therefore, the assessment of the level of innovativeness of the IOCP should include a technical and economic examination of design and structural solutions, which should be presented as a feasibility study of the selected innovative engineering solutions.

For the development of technical and economic argumentation of the proposed innovative solutions for a construction project, the following scope of work can be proposed for conducting an expert assessment using the point-rating method:

1. Architectural and design audit: development and assessment of the novelty of spaceplanning and design solutions.

2. Technology audit: development and assessment of the novelty of building technological solutions and applied building materials.

3. Substantiation of technological calculations.

4. Assessment of the level of competence of the project management team.

5. Economic assessment.

6. Environmental expertise.

7. Final assessment of the level of innovation of the project.

Based on the work of the expert group, a conclusion is drawn up on the level of application of innovative solutions and their economic efficiency during the estimated period of construction and operation of the future facility.

\section{Discussions}

The proposed algorithm for identifying the level of innovativeness of a complex capital construction object and its acceptance for financing from the budgets of the corresponding level should be supplemented with indicators of risk probability. 
It is known fact that the intensity of an innovation is determined by the novelty of its concept and the technology used for implementation. The higher the degree of novelty, the higher the intensity and associated risk (Figure 2).

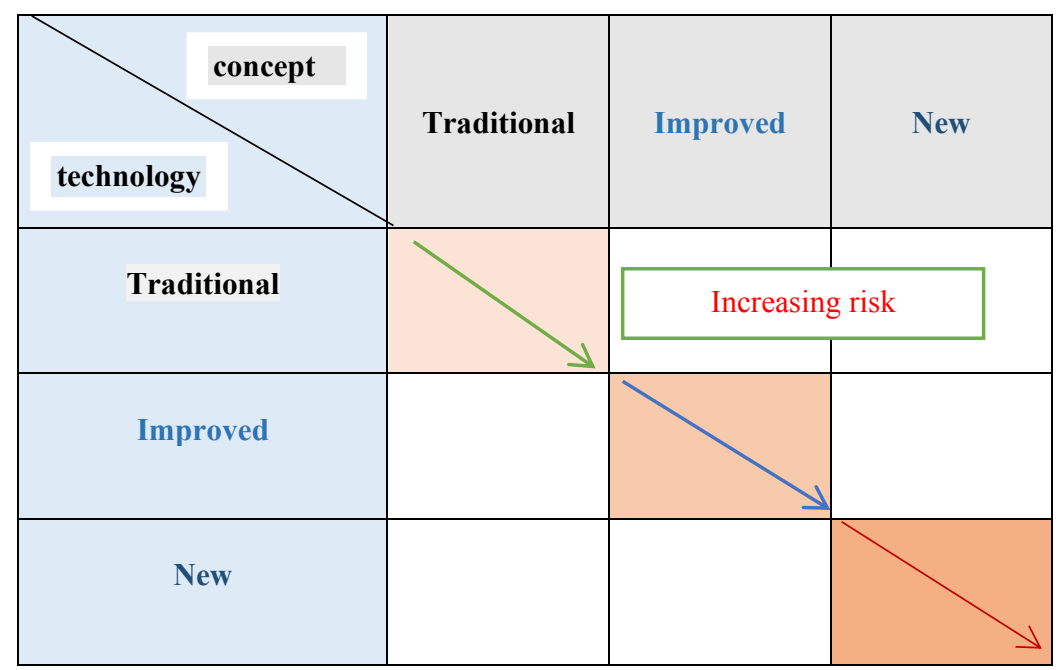

Fig. 2. Matrix of intensity of innovation and risk of application in practice

The main indicators used to select the best option for the project event with the uncertainty of some data are the indicators of the expected integral effect $\boldsymbol{E}_{\text {exp }}$.

If the probabilities of various conditions for project implementation are known, then the expected integral effect is calculated using the mathematical expectation formula:

$$
E_{\text {exp }}=\sum_{i=1}^{n} E_{i} P_{i}
$$

$E_{\text {exp }}$ - expected integral effect from the implementation of an innovative project

$E_{i}$ - integral effect at $i-t h$ condition of implementation;

$P_{i}-$ probability of this condition being realized

In the case of a complex innovative construction project, it is necessary to take into account the risk component:

$$
E_{\text {exp }}=\alpha E_{\text {max }}+(1-\alpha) E_{\text {min }}
$$

$E_{\text {exp }}$ - expected integral effect from the implementation of a complex innovative Project;

$E_{\text {max }}, E_{\text {min }}$ - the largest and the smallest of the mathematical expectations

of the integral effect for admissible probability distributions ;

$\alpha-$ a special standard to take into account the uncertainty of the effect, reflecting the system of preferences of the relevant participant in the implementation of a complex construction project in conditions of uncertainty.

The recommended value is 0.3 . 


\section{Conclusion}

It should be noted that forecasting and assessing possible cost results, taking into account the uncertainty factor, is the most difficult practical issue in assessing the effectiveness of an innovative project.

\section{References}

1. V. Politi. AISC (Adv. in Intell. Syst. and Comput.). 983, 116-126. (2019),

2. G. Solari. Springer Tracts in Civil Engineering. pp. 655-801. (2019).

3. E. Kuicheva, A. Popov. Regional Research of Russia (Road Town, United Kingdom), 6, no.1, pp. 9-20 (2017)

4. T. Hagerstrand. Innovation Diffusion as a Spatial Process, Chicago, IL: Univ. Chicago Press, 1968.

5. E.M. Rogers. Diffusion of Innovations, New York: Simon and Schuster, 2010, 4th ed.

6. E. Nezhnikova. Proc. Eng. 165, 1300-130. (2016).

7. E. Nezhnikova: Organizational-economic mechanism of formation of strategic priorities of housing construction development. IOP Conference Series: Earth and Environmental Science, 90, p. 012162 (2017)

8. F. Sleznov, Regional Research of Russia, 10, no.1, 97-106 (2020)

9. Comin, D.A., Dmitriev, M., and Rossi-Hansberg, E., The Spatial Diffusion of Technology, Cambridge, Ma: Natl. Bureau Econ. Res., (2012).

10. B. Zhikharevich., O. Rusetskaya, Regional Research of Russia (Road Town, United Kingdom), 8, no. 1, pp. 31-42 (2018).

11. V. Kosarev, P. Pavlov, and A. Kaukin, Ekon. Polit., 14, no. 5, pp. 144-149 (2019).

12. D. Morkovkin, D. Lopatkin, T. Shushunova.N., B. Sharipov, A. Gibadullin. Formation of the conditions for the development of innovation in Journal of Physics: Conference Series, IOP Publishing ([Bristol, UK], England), vol. 1515, no. 3, p. 032002 (1-6) (2020). 